\title{
Pilot Study of Smartphone Infrared Pupillography and Pupillometry
}

\author{
Omar Solyman $\mathbb{D}^{1-3}$, Mokhtar Mohamed Ibrahim Abushanab $\mathbb{D}^{\prime}$, Andrew R Carey $\mathbb{D}^{2}$, \\ Amanda D Henderson ${ }^{2}$ \\ 'Research Institute of Ophthalmology, Giza, Egypt; ${ }^{2}$ Wilmer Eye Institute, Johns Hopkins University School of Medicine, Baltimore, MD, USA; \\ ${ }^{3}$ Department of Ophthalmology, Qassim University Medical City, Al-Qassim, Saudi Arabia \\ Correspondence: Omar Solyman, Tel +20 I009350I0I, Email o.solyman@rio.edu.eg
}

Purpose: To describe and validate a novel portable smartphone-based infrared pupillographer.

Materials and Methods: A prototype infrared smartphone pupillographer device was custom designed for this project. Infrared video and photo pupillography were attempted on 12 patients with different clinical pupillary examination findings. Captured pupillography media files were assessed by three masked investigators, and the agreement between their qualitative clinical evaluation was tested against the evaluation of the neuro-ophthalmologist who performed the real-time examination and pupillography. Quantitative measurements of the pupillary diameter were performed by three investigators using a custom designed smartphone application on three different smartphones and on a personal computer. Measurements obtained by the three investigators using the smartphone and the desktop computer were compared.

Results: Infrared video pupillography of high quality was successfully captured for light and near pupillary reflexes, and infrared still photographs were obtained in light and dark conditions in 23 eyes of the 12 patients. Examination findings included relative afferent pupillary defect $(n=5)$, normal pupillary examination $(n=4)$, anisocoria $(n=2)$, and relative afferent pupillary reflex by reverse $(n$ $=1$ ). There was $100 \%$ agreement in the qualitative pupillary evaluation of the masked investigators compared with real time clinical examination. Quantitative measurements of pupillary size obtained on the smartphone and desktop computer showed excellent agreement among the three investigators with intraclass correlation (ICC) coefficient ranging from $0.982-0.986(\mathrm{P}<0.001)$ and $0.995(\mathrm{P}<0.001)$ for the smartphone and the desktop computer groups, respectively. Level of agreement ranged between -0.27 and 0.32 . Mean pupil diameter errors were $0.03 \pm 0.15 \mathrm{~mm}$ between groups $(\mathrm{P}=0.248)$.

Conclusion: This pilot study demonstrates the feasibility of smartphone-based infrared pupillography for high quality photo and video documentation of pupillary examination at the bedside and in the clinic with accurate and reproducible measurements of the pupillary size in light and dark conditions.

Keywords: smartphone pupillography, infrared pupillometry, smartphone pupillometry, anisocoria, afferent pupillary defect

\section{Introduction}

Pupil evaluation is an important component of comprehensive ophthalmologic and neurologic examinations. Qualitative physical examination of the pupillary light reflex (PLR) and measurement of pupillary sizes with pupil gauges is usually adequate for the ophthalmology clinic setting, however, considerable inter-examiner variations may exist. ${ }^{1}$ Infrared pupillometers have been shown to be more accurate than physical examination in certain settings, such as in critical care units and during anesthesia. ${ }^{2}$ Although portable pupillographers were introduced over 30 years ago, they did not gain much clinical popularity. ${ }^{3}$ Smartphone use for pupillography and pupillometry has been an area of interest for its ubiquity and convenience. ${ }^{4}$ Pupillometry is reliant on defining the border between the iris and the pupil. Infrared videography is the gold standard method for pupillography as it works for different iris colors and across the range of illumination conditions to provide high contrast between the pupillary and the iris margins. Using visible light spectrum for pupillography is markedly limited in the evaluation of the pupil in dim/dilating states, particularly in patients with dark colored irides. ${ }^{5}$ Herein we report and validate the use of a smartphone-based infrared pupillographer with two 
synchronized mini-infrared camera modules coupled with a compatible smartphone. We also review previous reports of different techniques of smartphone pupillography and pupillometry and contrast differences among them.

\section{Methods}

This study was approved by the Johns Hopkins University School of Medicine Institutional Review Board and conducted in accordance with the Declaration of Helsinki. Camera modules consisting of two or more synchronized cameras are commercially available for use as multiple scene webcams, security surveillance systems, and as a means to obtain virtual reality photography. We used this existing technology in the form of a custom-designed camera consisting of a dual synchronized camera module with two infrared minicameras with 2 megapixels of resolution and 30 degrees of angle of view each, with peak sensitivity at $850 \mathrm{~nm}$ wavelength (Dual synchronized camera module, Shenzhen Kayeton Technology Co., Ltd, Shenzhen, China). The camera module was equipped with a built-in mini-infrared light source and micro-USB output. When connected to a compatible smartphone, the two mini cameras and the infrared light source are powered directly by the smartphone battery, without the need for external power supply. We used the CameraFi Android application (https://www.camerafi.com) to capture and save still images and 30 frame-per-second videos of the pupillary examination. The smartphone-camera complex could be either hand-carried (Figure 1A), allowing for use at the bedside, or mounted on the slit lamp (Figure 1B) for optimal video recording stabilization.

After connection with a Samsung Galaxy S5 Android smartphone (Samsung, Yeongtong, Suwon, South Korea), infrared video and photo pupillography were attempted on 12 patients with different pupillary examination findings. Welch Allyn 3.5 V halogen fiber-optic transilluminator (Welch Allyn Inc, Skaneateles Falls, New York, USA) designed for general clinical pupillary examination was used to test for pupillary light reflex and to obtain pupillary snapshots in light. Captured pupillography media files were replayed on the smartphone by three masked ophthalmologists, and the agreement between their qualitative clinical evaluation was tested against the evaluation of the neuro-ophthalmologist who performed the real-time examination. Quantitative measurements of the pupillary diameter were performed by three investigators on three different smartphones using a custom designed (the Wadjet Pupil Gauge smartphone application) now available on both Android ${ }^{6}$ and $\operatorname{iOS}^{7}$ smartphone application stores and Measura X Windows computer application on a desktop computer (https://www.microsoft.com/en-us/p/measura-x/9nblggh6hhd3?activetab=pivot:overviewtab).

Data were analyzed using IBM SPSS software package version 20.0 (IBM Corp, Armonk, NY, USA). Quantitative data were described using mean and standard deviation. Significance of the obtained results was judged at the $5 \%$ level.

Intraclass correlation coefficient (ICC) was used to evaluate the agreement among the three investigators' measurements of pupillary diameter using the smartphone and desktop computer. ICC below $0.50 \mathrm{Z}$ was considered poor

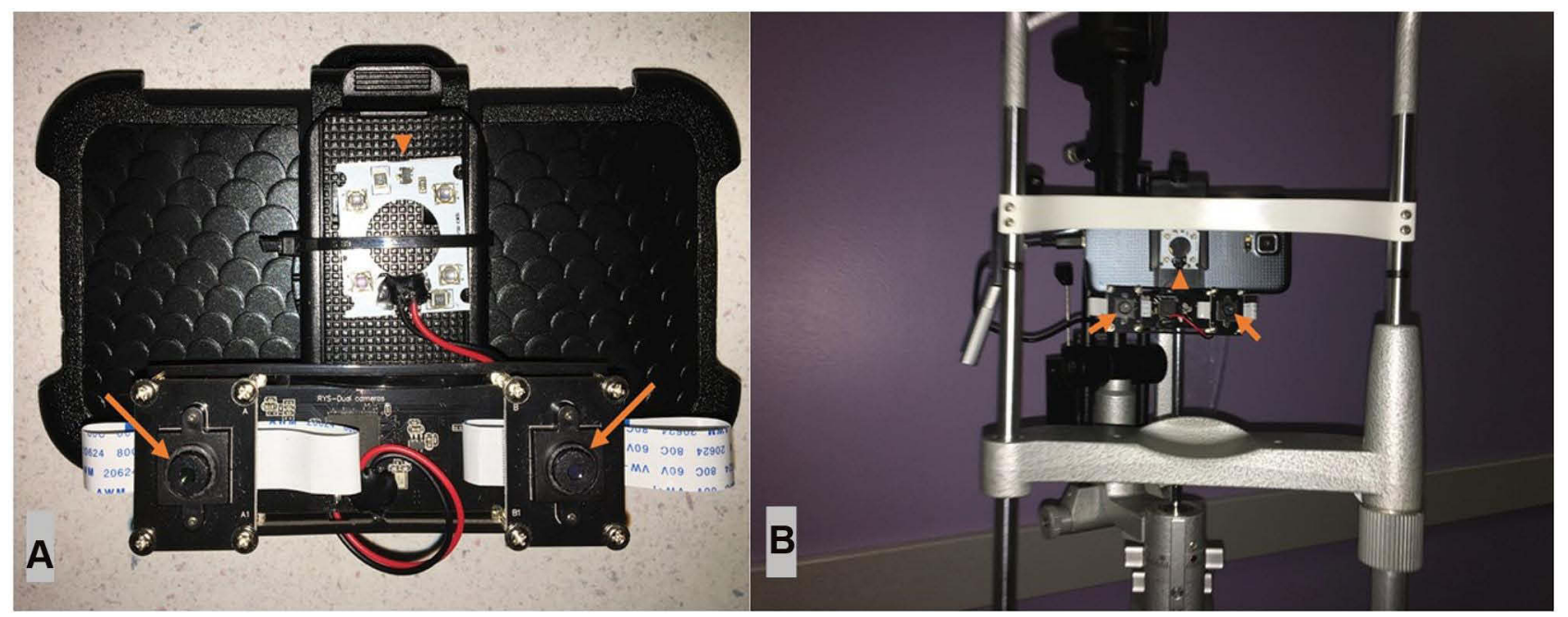

Figure I (A) Infrared camera module connected to smartphone. (B) Infrared camera module-smartphone complex mounted on slit lamp for steadier pupillography. Two mini-infrared cameras (arrows) and infrared light source (arrowhead) are shown. 


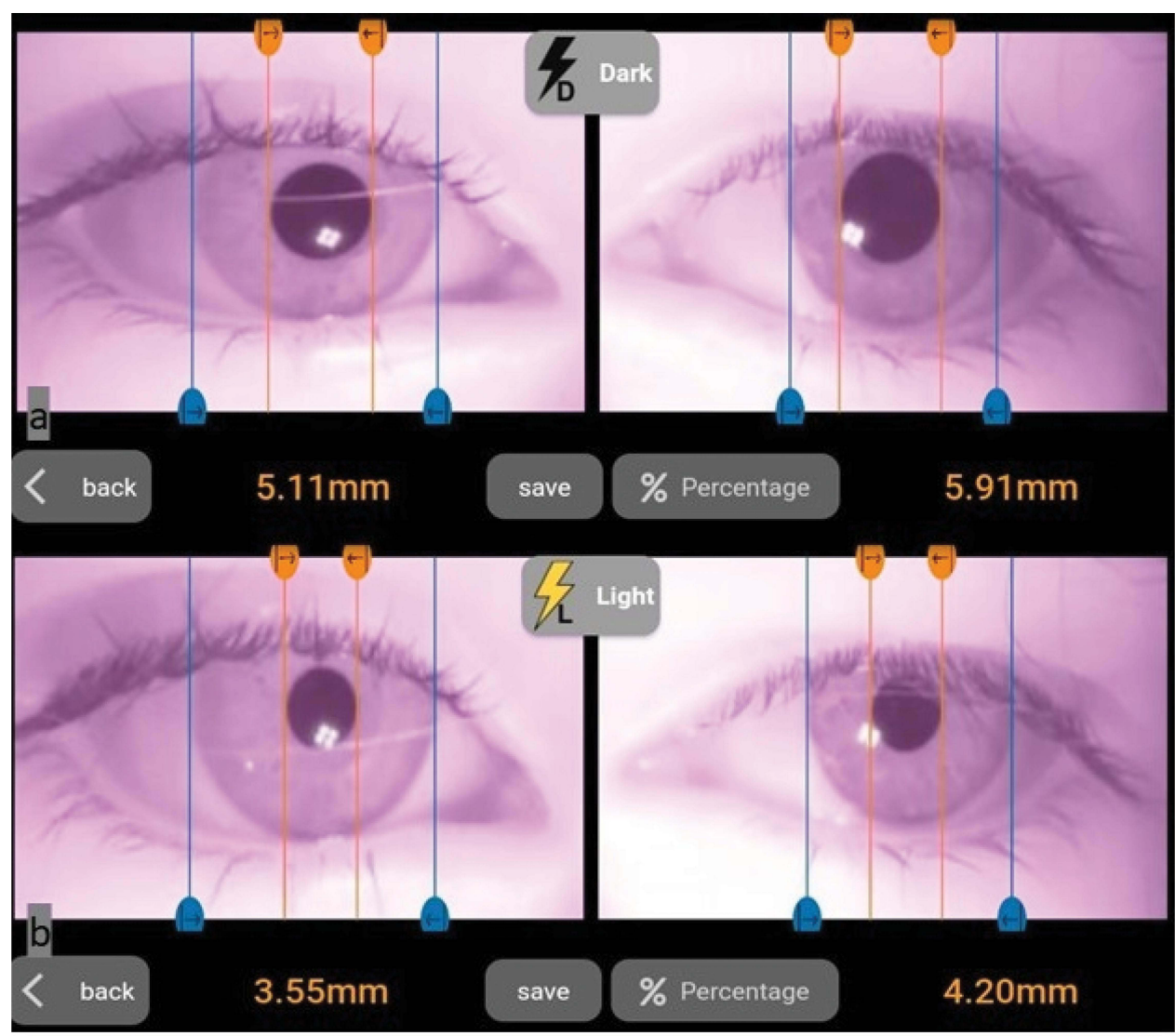

Figure 2 Measurement of pupillary diameter of both eyes in dark (A) and in light (B) illumination conditions using our custom designed application in a patient with anisocoria.

agreement; 0.50 to less than $0.75 \mathrm{Z}$ moderate agreement; 0.75 to $0.90 \mathrm{Z}$ good agreement; and above $0.90 \mathrm{Z}$ excellent agreement. A P-value less than 0.05 was considered statistically significant.

Paired $t$-test was used to compare the mean of measurements of pupillary diameter between the computer and the smartphone. Bland Altman plot and one sample $t$-test were used for evaluation of agreement between the mean pupillary diameter measurements using the smartphone application versus desktop computer.

Table I Intraclass Correlation Coefficient for Pupillary Diameter Measurements When Using Computer and When Using Smartphone $(n=46)$

\begin{tabular}{|l|c|c|c|c|c|c|}
\hline \multirow{2}{*}{} & \multicolumn{3}{|c|}{ Computer Measurements } & \multicolumn{3}{c|}{ Smartphone Measurements } \\
\cline { 2 - 7 } & ICC & $95 \%$ CI & P & ICC & $95 \%$ CI & P \\
\hline Overall & 0.995 & $0.992-0.997$ & $<0.00 I^{*}$ & 0.984 & $0.975-0.99$ I & $<0.00 I^{*}$ \\
\hline I vs 2 & 0.995 & $0.99 I-0.997$ & $<0.00 I^{*}$ & 0.982 & $0.968-0.990$ & $<0.00 I^{*}$ \\
\hline I vs 3 & 0.995 & $0.99 I-0.997$ & $<0.00 I^{*}$ & 0.985 & $0.974-0.992$ & $<0.00 I^{*}$ \\
\hline 2 vs 3 & 0.995 & $0.99 I-0.997$ & $<0.00 I^{*}$ & 0.986 & $0.974-0.992$ & $<0.00 I^{*}$ \\
\hline
\end{tabular}

Note: *Statistically significant at $P \leq 0.05$.

Abbreviations: $\mathrm{Cl}$, confidence interval; ICC, intraclass correlation coefficient. 


\section{Results}

Infrared pupillography videos of high quality were captured for light and near pupillary reflexes, and infrared still photographs were obtained in light and dark conditions in 23 eyes of 12 patients. The two minicamera design allowed simultaneous eye-focused recording, sparing the rest of the face for patient privacy.

A total of 12 pupillography videos were assessed by three masked investigators for qualitative evaluation. Videos demonstrated relative afferent pupillary defect $(n=5)$, normal pupillary examination $(n=4)$, anisocoria $(n=2)$, and relative afferent pupillary reflex by reverse $(\mathrm{n}=1)$ (Supplementary Videos $1-\underline{4}$ and Figure 2). There was $100 \%$ agreement in the qualitative pupillary evaluation of the masked investigators compared with real time clinical examination.

A total of 24 static pupillography images (a photograph in light and in dark of both eyes for each patient) was evaluated by three masked investigators for pupillary size measurement. Quantitative measurements of pupillary size obtained on the smartphone and on the desktop computer showed excellent agreement among the three investigators with ICC ranging between 0.982-0.986 ( $<<0.001)$, and of 0.995 ( $\mathrm{P}<0.001)$ for the smartphone and the desktop computer groups, respectively, with a level of agreement ranging between -0.27 and 0.32 , and mean pupil diameter errors of $0.03 \pm$ $0.15 \mathrm{~mm}$ between both groups (not statistically significant, $\mathrm{P}=0.248$ ) (Tables 1 and 2 and Figure 3).

\section{Discussion}

Various methods of smartphone pupillography/pupillometry have been described, each with its own limitations. Several groups have described the use of the unmodified rear-facing camera and visible light spectrum from light emitting diode (LED) flashlight of smartphones for pupillography and pupillometry (Table 3). ${ }^{4-12}$ Some have described momentary illumination of the pupils with flashlights to capture pupillary images during different stages of PLR, while others captured pupillography videos during continuous LED flashlight illumination of the pupils. ${ }^{4,8-10}$ Shin et al. ${ }^{4}$ introduced a smartphone application that acquires five sequential images using the rear-facing camera and flashlight to illuminate the pupil during PLR. They reported agreement between the images of their application and qualitative examination, in terms of pupil size and degree of response. ${ }^{4}$ McAnany et al. used an iPhone application (Sensitometer ${ }^{\mathrm{TM}}$ test) ${ }^{11}$ that generates two flashlights and records the PLR using the rear-facing camera of the same iPhone. The light stimulus consisted of two

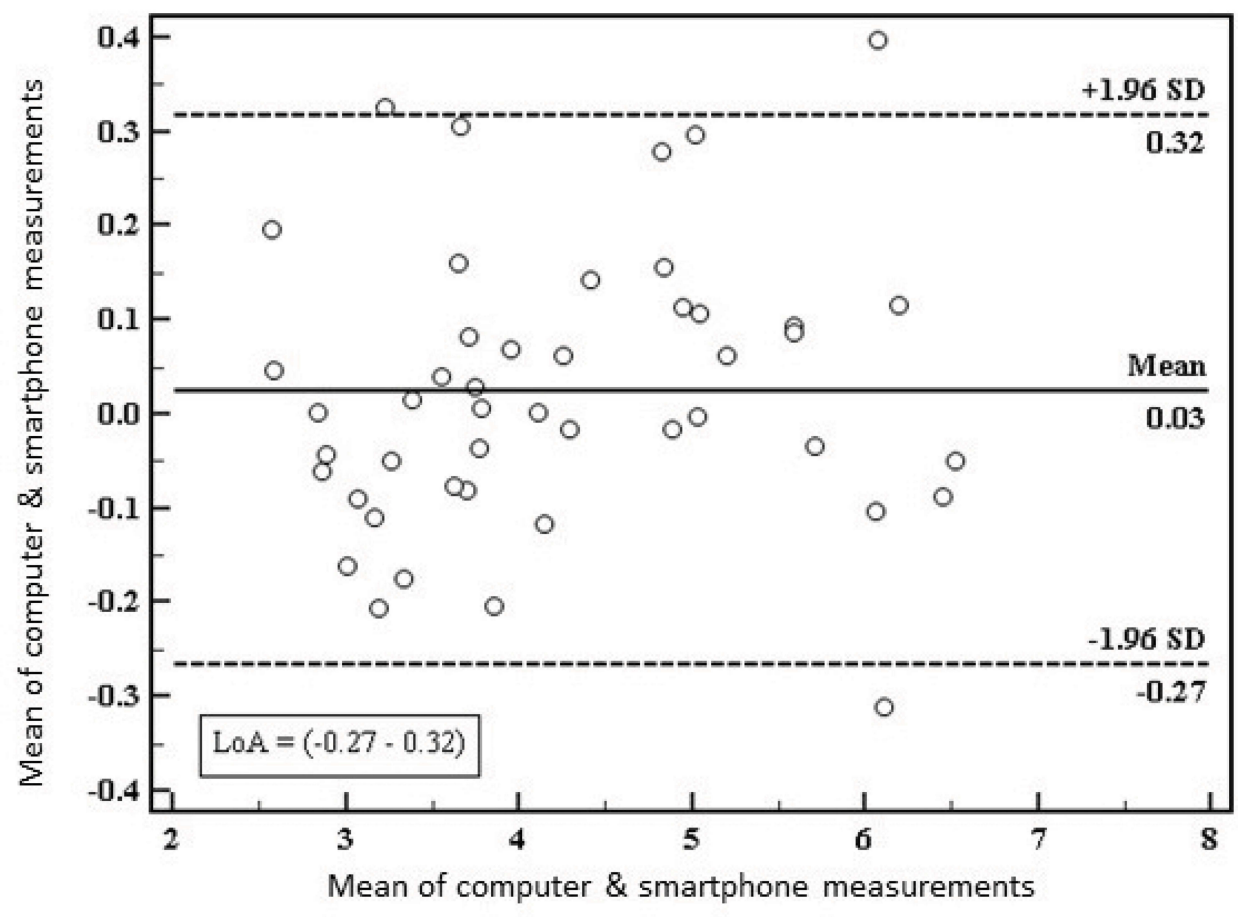

Figure 3 Bland Altman plot and one sample t-test for agreement between smartphone and desktop-based measurements of pupillary diameter. 
Table 2 Comparison Between Desktop and Smartphone-Based Pupillary Diameter Measurements

\begin{tabular}{|l|c|c|c|c|}
\hline & Desktop & Smartphone & T & P \\
\hline Mean \pm SD & $4.27 \pm 1.14$ & $4.24 \pm 1.12$ & 1.169 & 0.248 \\
\hline Difference & \multicolumn{2}{|c|}{$0.03 \pm 0.15$} & & \\
\hline
\end{tabular}

Note: $t$, Paired $t$-test; P, P value for comparing desktop and smartphone measurements.

Table 3 A Summary of Prior Reports of Smartphone Use in Pupillography and Pupillometry

\begin{tabular}{|c|c|c|c|c|c|c|}
\hline & $\begin{array}{c}\text { Visible } \\
\text { Light } \\
\text { Source }\end{array}$ & $\begin{array}{l}\text { Infrared } \\
\text { Light } \\
\text { Source }\end{array}$ & Camera & Software & Hardware Add-on & Goal \\
\hline Shin et al. ${ }^{4}$ & $\begin{array}{l}\text { Smartphone } \\
\text { LED }\end{array}$ & None & $\begin{array}{l}\text { Smartphone } \\
\text { camera }\end{array}$ & Custom, iPhone-based & None & $\begin{array}{l}\text { General } \\
\text { pupillography }\end{array}$ \\
\hline McAnany et al. ${ }^{8}$ & $\begin{array}{l}\text { Smartphone } \\
\text { LED }\end{array}$ & None & $\begin{array}{l}\text { Smartphone } \\
\text { camera }\end{array}$ & $\begin{array}{l}\text { Sensitometer }{ }^{\mathrm{TM}} \mathrm{iPhone}- \\
\text { based }\end{array}$ & None & $\begin{array}{l}\text { General } \\
\text { pupillometry }\end{array}$ \\
\hline Neice et al. ${ }^{9}$ & $\begin{array}{l}\text { Smartphone } \\
\text { LED }\end{array}$ & None & $\begin{array}{l}\text { Smartphone } \\
\text { camera }\end{array}$ & Custom, iPhone-based & None & $\begin{array}{l}\text { Study of pupillary } \\
\text { hippus in TBI }\end{array}$ \\
\hline McKay et al. ${ }^{10}$ & $\begin{array}{l}\text { Smartphone } \\
\text { LED }\end{array}$ & None & $\begin{array}{l}\text { Smartphone } \\
\text { camera }\end{array}$ & $\begin{array}{l}\text { Commercially available } \\
\text { iPhone application by } \\
\text { BL; Brightlamp Inc., } \\
\text { Indianapolis, IN, USA }\end{array}$ & None & $\begin{array}{l}\text { General } \\
\text { pupillometry }\end{array}$ \\
\hline $\begin{array}{l}\text { Mariakakis } \\
\text { et al. }{ }^{5}\end{array}$ & $\begin{array}{l}\text { Smartphone } \\
\text { LED }\end{array}$ & None & $\begin{array}{l}\text { Smartphone } \\
\text { camera }\end{array}$ & $\begin{array}{l}\text { iPhone-based trained } \\
\text { convolutional neural } \\
\text { networks }\end{array}$ & $\begin{array}{l}\text { VR set-like 3D } \\
\text { printed phone } \\
\text { adapter }\end{array}$ & $\begin{array}{l}\text { General } \\
\text { pupillometry }\end{array}$ \\
\hline Calandra et al. ${ }^{12}$ & $\begin{array}{l}\text { Smartphone } \\
\text { LED }\end{array}$ & None & $\begin{array}{l}\text { Smartphone } \\
\text { camera }\end{array}$ & $\begin{array}{l}\text { Sober-Eye application, } \\
\text { iPhone-based }\end{array}$ & None & $\begin{array}{l}\text { Self-assess pupillary } \\
\text { reaction to light to } \\
\text { identify drug/ } \\
\text { alcohol intoxication }\end{array}$ \\
\hline Piaggio et al. ${ }^{13}$ & $\begin{array}{l}\text { Smartphone } \\
\text { LED }\end{array}$ & None & $\begin{array}{l}\text { Smartphone } \\
\text { camera }\end{array}$ & Custom, Android-based & None & $\begin{array}{l}\text { General } \\
\text { pupillometry for } \\
\text { low resource } \\
\text { setting }\end{array}$ \\
\hline Kim et al. ${ }^{15}$ & $\begin{array}{l}\text { White LED } \\
\text { addons }\end{array}$ & $\begin{array}{l}\text { Infrared LED } \\
\text { addons }\end{array}$ & $\begin{array}{l}\text { Smartphone } \\
\text { camera }\end{array}$ & Custom, Android-based & $\begin{array}{l}\text { White and infrared } \\
\text { LEDs }\end{array}$ & $\begin{array}{l}\text { General } \\
\text { pupillometry }\end{array}$ \\
\hline Chang et al. ${ }^{14}$ & $\begin{array}{l}\text { Smartphone } \\
\text { LED }\end{array}$ & $\begin{array}{l}\text { Externally } \\
\text { powered } \\
\text { infrared } \\
\text { source }\end{array}$ & $\begin{array}{l}\text { Infrared camera } \\
\text { connected to } \\
\text { a laptop }\end{array}$ & $\begin{array}{l}\text { Custom laptop } \\
\text { MATLAB }\end{array}$ & $\begin{array}{l}\text { Slit lamp bound } \\
\text { infrared camera, } \\
\text { a laptop, and an } \\
\text { infrared light source }\end{array}$ & $\begin{array}{l}\text { General } \\
\text { pupillography and } \\
\text { pupillometry }\end{array}$ \\
\hline Our design & $\begin{array}{l}\text { External pen } \\
\text { light source }\end{array}$ & $\begin{array}{l}\text { Mini infrared } \\
\text { source } \\
\text { powered by } \\
\text { the } \\
\text { smartphone }\end{array}$ & $\begin{array}{l}\text { Two } \\
\text { synchronized } \\
\text { minicameras } \\
\text { connected to } \\
\text { the smartphone }\end{array}$ & $\begin{array}{l}\text { CameraFi smartphone } \\
\text { app to capture videos/ } \\
\text { pictures } \\
\text { Custom designed Pupil } \\
\text { Gauge Smartphone } \\
\text { application }\end{array}$ & $\begin{array}{l}\text { Pocket size device } \\
\text { consisting of } 2 \\
\text { minicameras and } \\
\text { mini-infrared light } \\
\text { source }\end{array}$ & $\begin{array}{l}\text { General } \\
\text { pupillography and } \\
\text { pupillometry }\end{array}$ \\
\hline
\end{tabular}


flashes of light: an initial light stimulus of 3-second duration (to elicit pupillary constriction), followed by a second brief flash of 0.25 -second duration to illuminate the pupil and allow for momentary photography. The authors reported high agreement between the pupillometry results from their application and a simultaneous recording using an infrared camera, in terms of dark adapted steady-state pupil size, minimum constricted pupil size, and size of the pupil during the dilation. ${ }^{8}$ Shin et al. and McAnany et al. reported strong correlation between their smartphone pupillography and qualitative physical examination and infrared pupillography, respectively. Neice et al. developed an iPhone-based software to study pupillary hippus in one eye at a time using the rear-facing camera, aided by continuous background illumination from the LED flashlight source, and compared their results with measurements from a dedicated infrared pupillometer of the other eye. ${ }^{9}$ The iPhone-based pupillometer failed to identify the pupil or iris in 6 of 26 study eyes compared with the infrared pupillometer, which was attributed to its reliance on visible light and variation of iris color among study participants. ${ }^{9}$ McKay et al. compared the commercially available Brightlamp iPhone application (BL; Brightlamp Inc., Indianapolis, IN, USA) with a portable infrared pupillometer and demonstrated poor reproducibility of the application. ${ }^{10}$ Calandra et al. ${ }^{12}$ reported that the Sober-Eye application (SOBER-EYE Inc., Menlo Park - CA, USA), ${ }^{12}$ designed to self-assess pupillary reaction to a smartphone light flash as a measure of level of impairment from drugs or alcohol, is highly correlated with manual measurements. ${ }^{9}$ Typically, non-infrared methods of pupillography (i.e., those reliant on visible light) are limited in evaluation of the dim/dilating states of the pupil, particularly in patients with dark irides, and this characteristic limits the clinical application of these devices.

Piaggio et al. and Mariakakis et al. proposed two novel methods to help the non-modified smartphone camera capture pupillary reactions in dim/dilating stages without the need for additional visible light illumination using image postprocessing and deep learning, respectively. ${ }^{5,13}$ Piaggio et al. reported converting video frames into gray-scale and binarizing them according to empirically set thresholds for different degrees of illumination to increase the contrast between pupil and iris. They tested their hypothesis in PLR in 11 volunteers with light brown irides and reported that their proposed application performed as well as the ground truth manual measurements and better than a commercial infrared pupillometer. The authors acknowledged that the performance of the application was evaluated only on subjects with light brown eyes, and that darker irides may be more challenging for pupillometers relying on visible light only. ${ }^{13}$ Mariakakis et al. trained convolutional neural networks to study pupillary light reaction to develop an iPhone-based pupillography software to screen for traumatic brain injury ("pupil screen"). Included eyes had different degrees of iris color, including dark irides. A virtual reality-like 3D printed box was used as a housing for the iPhone to eliminate ambient lighting and control the distance between the subject's eyes and the camera of the iPhone, thus standardizing the measurements of the application. ${ }^{5}$ They reported high correlation between pupil screen measurements and ground truth PLR curves from manual annotations with mean pupil diameter errors of $+0.24 \mathrm{~mm},+0.27 \mathrm{~mm}$, and $+0.07 \mathrm{~mm}$ for blue, brown, and mixed eyes, respectively. However, they also reported a 17\% disagreement of manual measurements between the annotations of the two masked investigators, thus demonstrating the difficulty in delineating dim pupillary contour raw data in dark irides.

Ideally, smartphone pupillography would be feasible without additional hardware, to achieve ubiquity and portability. Apart from Mariakakis et al., the aforementioned reports used a smartphone's rear-facing camera and LED flashlight for visible light pupillography without accessory hardware. Clearly, the use of bulky or stationary accessory hardware limits portability. Additionally, challenges regarding the use of visual light to evaluate dim/dilating pupil states and dark irides provide an impetus for further development of infrared imaging for accurate pupillography.

Chang et al. and Kim et al. described the use of accessory hardware enabled with an infrared light source to improve the contrast between the pupillary and iris margins. While the use of infrared illumination addressed the challenges associated with use of visible light for pupillography, their designs were limited by bulky external hardware and phonespecific characteristics, respectively. ${ }^{14,15}$

In this study we used a custom designed dual synchronized infrared minicamera smartphone attachment to obtain high quality smartphone-based video and photo pupillography media with clear delineation of the margin of the pupil. Although an accessory hardware is required in this approach, our accessory device is of a pocket size and does not hinder portability of this pupillography technique. The use of the dual camera design allows eye-focused recording with suitable magnification of the pupil and sparing of the rest of the patient's face for patient privacy. 
Web-based applications that can perform automated pupillometry on live camera or video streams are described in the literature. An example is the open source MEYE tool which uses convolutional neural networks to detect and measure real-time changes in pupil size both in humans and animals. ${ }^{16}$ Unfortunately, we could not integrate it with our device because the MEYE tool is designed for evaluation of one pupil at a time and could not identify both pupils from our camera design. Our custom designed software allows user friendly immediate post recording measurement of the pupil diameter with excellent reproducibility and high degree of accuracy. The examiner needs to align four vertical bars with the corresponding margins of the pupil and the limbus of the tested eye on the smartphone's touch screen, then the pupillary diameter can be directly calculated as a percentage of white-to-white diameter of the corresponding eye or in millimeters based on a fixed consideration of $12 \mathrm{~mm}$ corneal diameter for each eye (Figure 2).

Advantages of our prototype include its small size and that it does not require an external power supply, as it powers directly from the smartphone attachment, which enhances its portability. The use of dedicated infrared cameras provides high quality pupillography with optimal contrast between the iris and pupillary margins for accurate and reproducible pupillary assessment in patients with all degrees of iris colors under a wide range of illumination levels. Only one eye of 24 could not be directly imaged because of dense corneal scarring (Supplementary Video 4), which also precluded direct pupillary examination; however, pupillography of the other pupil showed relative afferent pupillary defect in the eye with corneal scarring.

Another advantage is the simultaneous recording of pupillary reactions from both eyes which maximizes the clinical value of this approach in ophthalmic and neuro-ophthalmic clinical practice. Commercially available portable pupillometers are designed to measure latency, reflex amplitude and constriction velocity of one pupil at a time following a brief flash of visible light. ${ }^{10,17,18}$ Although these monocular data may be valuable in certain clinical settings such as intensive care units, concussion follow-up, and perioperative medicine, they are of lower yield in clinical ophthalmology and neuro-ophthalmology.

Limitations of our current prototype include a lack of real-time automated analysis. Although pupillary measurements are not entirely automated, our custom designed application allows immediate post capture measurements, is easy to use, and provided excellent reproducibility with high degree of accuracy. Another limitation of the current prototype is the lack of autofocus capability, which can be improved on future updates.

Future perspectives include software update with real-time analytic capabilities of both pupils to make the examination process faster and more convenient and provide additional quantitative data regarding the speed and latency of pupillary constriction and dilation.

\section{Conclusion}

This pilot study demonstrates and validates the feasibility of smartphone-based infrared pupillography with accurate and reproducible pupil size measurements both at the bedside and in the clinic across different conditions of illumination. The described technique offers a portable and affordable method of pupillary examination and documentation, which may have applications for telemedicine consultations, medical student and resident education, and documentation of pertinent exam findings.

\section{Acknowledgments}

The authors would like to thank Dr. Nada Osama Mohammed, MD and Dr. Sheren Mohamed Abo Shanab, MD ophthalmologists from Qassim University Medical City and Research Institute of Ophthalmology respectively for their participation in pupillary measurement and data collection of this study.

\section{Funding}

There is no funding to report.

\section{Disclosure}

Omar Solyman reports patent 625/2021 pending to Egyptian IP office; pocket smartphone infrared pupillographer pending patent application number 2138/2021 at the Egyptian Patent and Trade Mark Office; and The Pupil Gauge 
application is designed and owned by the first author. The authors report no other potential conflicts of interest for this work.

\section{References}

1. Wilhelm H, Wilhelm B. Clinical applications of pupillography. J Neuro-Ophthalmol. 2003;23(1):42-49. doi:10.1097/00041327-200303000-00010

2. Couret D, Boumaza D, Grisotto C, et al. Reliability of standard pupillometry practice in neurocritical care: an observational, double-blinded study. Crit Care. 2016;20:99. doi:10.1186/s13054-016-1239-z

3. Larson MD, Behrends M. Portable infrared pupillometry: a review. Anesth Analg. 2015;120(6):1242-1253. doi:10.1213/ANE.0000000000000314

4. Shin YD, Bae JH, Kwon EJ, Kim HT, Lee TS, Choi YJ. Assessment of pupillary light reflex using a smartphone application. Exp Ther Med. 2016;12(2):720-724. doi:10.3892/etm.2016.3379

5. Mariakakis A, Baudin J, Whitmire E, et al. PupilScreen: using smartphones to assess traumatic brain injury. Proc ACM Interact Mob Wearable Ubiquitous Technol. 2017;1(3):1-27. doi:10.1145/3131896

6. Google play. Available from: https://play.google.com/store/apps/details?id=com.wadjetzigadget.pupil. Accessed December 15, 2021.

7. Pupil gauge - Wadjet. App Store. Available from: https://apps.apple.com/us/app/pupil-gauge-wadjet/id1598406918. Accessed December 15, 2021.

8. McAnany JJ, Smith BM, Garland A, Kagen SL. iPhone-based Pupillometry: a novel approach for assessing the pupillary light reflex. Optom Vis Sci. 2018;95(10):953-958. doi:10.1097/OPX.0000000000001289

9. Neice AE, Fowler C, Jaffe RA, Brock-Utne JG. Feasibility study of a smartphone pupillometer and evaluation of its accuracy. J Clin Monit Comput. 2020;35(6):1269-1277. doi:10.1007/s10877-020-00592-x

10. McKay RE, Kohn MA, Schwartz ES, Larson MD. Evaluation of two portable pupillometers to assess clinical utility. Concussion. 2020;5(4): CNC82. doi: $10.2217 / \mathrm{cnc}-2020-0016$

11. Kagen SL, McAnany J, Smith B, Garland A. The sensitometerTM test: new iPhone app accurately measures human smooth muscle reactivity. J Allergy Clin Immunol. 2018;141(2):AB96. doi:10.1016/j.jaci.2017.12.308

12. Calandra D, Di Martino S, Riccio D, Visconti A Smartphone based pupillometry: an empirical evaluation of accuracy and safety. International Conference on Image Analysis and Processing; Springer, Cham; 2017:443. doi:10.1007/978-3-319-68548-9_40

13. Piaggio D, Namm G, Melillo P, Simonelli F, Iadanza E, Pecchia L. Pupillometry via smartphone for low-resource settings. Biocybern Biomed Eng. 2021;41(3):891-902. doi:10.1016/j.bbe.2021.05.012

14. Chang LYL, Turuwhenua J, Qu TY, Black JM, Acosta ML. Infrared Video Pupillography Coupled with Smart Phone LED for Measurement of Pupillary Light Reflex. Front Integr Neurosci. 2017;11:6. doi:10.3389/fnint.2017.00006

15. Kim TH, Youn JI. Development of a Smartphone-based Pupillometer. J Opt Soc Korea. 2013;17(3):249-254. doi:10.3807/JOSK.2013.17.3.249

16. Mazziotti R, Carrara F, Viglione A, et al. MEYE: web app for translational and real-time pupillometry. eNeuro. 2021;8(5):ENEURO.0122-21.2021. doi:10.1523/ENEURO.0122-21.2021

17. Joseph JR, Swallow JS, Willsey K, et al. Pupillary changes after clinically asymptomatic high-acceleration head impacts in high school football athletes. J Neurosurg. 2019:1-6. doi:10.3171/2019.7.JNS191272

18. Packiasabapathy S, Rangasamy V, Sadhasivam S. Pupillometry in perioperative medicine: a narrative review. Can J Anaesth J Can Anesth. 2021;68 (4):566-578. doi:10.1007/s12630-020-01905-Z

\section{Publish your work in this journal}

Clinical Ophthalmology is an international, peer-reviewed journal covering all subspecialties within ophthalmology. Key topics include: Optometry; Visual science; Pharmacology and drug therapy in eye diseases; Basic Sciences; Primary and Secondary eye care; Patient Safety and Quality of Care Improvements. This journal is indexed on PubMed Central and CAS, and is the official journal of The Society of Clinical Ophthalmology (SCO). The manuscript management system is completely online and includes a very quick and fair peer-review system, which is all easy to use. Visit http://www. dovepress.com/testimonials.php to read real quotes from published authors.

Submit your manuscript here: https://www.dovepress.com/clinical-ophthalmology-journal 